\title{
Breeding high energy grasses for Australia and New Zealand
}

\author{
K.F. SMITH ${ }^{1,4}$, A. STEWART ${ }^{2}$ and G. SPANGENBERG ${ }^{3,4}$ \\ ${ }^{1}$ Department of Primary Industries, Private Bag 105, Hamilton 3300, Victoria, Australia \\ ${ }^{2} P G G$ Wrightson, Kimihia Research Centre, Lincoln, New Zealand \\ ${ }^{3}$ Department of Primary Industries, Victorian Agribiosciences Centre, Bundoora 3083, Victoria, Australia \\ ${ }^{4}$ Molecular Plant Breeding Cooperative Research Centre, Bundoora 3083, Victoria Australia
}

kevin.f.smith@dpi.vic.gov.au

\begin{abstract}
There are currently a range of programmes breeding ryegrasses with enhanced water-soluble carbohydrate concentrations leading to enhanced metabolisable energy (ME) contents when this herbage is consumed by grazing ruminants. High ME concentrations in grasses have the potential to increase milk and meat production through improved energy supply and more efficient rumen fermentation. However, the first 'high sugar' grass cultivars sown in Australia and New Zealand have not always delivered the animal production benefits that have been realised when these cultivars were sown in the UK. This illustrates not only the need to develop agronomic practices that are suited to exploiting the potential of germplasm with high energy concentrations but also the need to not view the high energy trait in isolation from other breeding objectives such as adaptation, seasonal production and disease resistance.
\end{abstract}

Keywords: perennial ryegrass, carbohydrate, sugar, fructan, breeding

\section{Introduction}

The grazing industries in New Zealand and temperate Australia are based on the grazing of pasture to provide an efficient, cost-effective source of nutrients to grazing animals. While pasture provides the bulk of these nutrients, there are times when pasture does not meet the nutritional needs of animals, particularly during peak lactation and during periods of high animal growth rates in meat production systems. During such periods producers must rely on relatively expensive supplements such as grain or silage to maintain production.

Ruminants have evolved a digestive system that allows them to effectively extract energy from cellulosic feeds such as the cell walls of grasses. However, when the supply of readily fermentable carbohydrates is limiting, protein can be used inefficiently in the system. Most of the protein present in herbage is soluble and thus available for rapid degradation to ammonia in the rumen (Beever 1993). When sufficient energy is available, this ammonia is converted into microbial protein which is subsequently available to the ruminant. When there is insufficient energy available from herbage, the carbon skeletons from the protein will be used as an energy source and $\mathrm{N}$ will be lost to the system as ammonia. An imbalance between protein and energy levels in feed can also lead to an increase in methane production, thus causing a loss of dietary energy. At times this ammonia may reach toxic concentrations in the bloodstream of the animal. Thus, efficient utilisation of protein by ruminants depends on the synchronous supply of energy and protein for microbial biosynthesis (Beever 1993). Water-soluble carbohydrates in grasses form a ready source of this energy.

Plants accumulate soluble carbohydrates in a range of forms from simple sugars, such as fructose, glucose and sucrose, to longer chain storage carbohydrates (Van Soest 1982). In temperate grasses the storage carbohydrates are primarily fructans, while tropical grasses store nonstructural carbohydrates as starch or less commonly sucrose (Smouter \& Simpson 1989). Fructans are polymers of fructose that begin with a sucrose molecule; the structure and length of these fructan molecules is known to vary between grass species (Smouter \& Simpson 1989).

\section{Breeding 'high sugar' grasses in the UK}

The first major effort to breed perennial ryegrass cultivars with increased soluble carbohydrate concentrations was led by the team at the Institute of Grassland and Environmental Research (IGER) at Aberystwyth in the UK. It is important to note that although this suite of cultivars and experimental lines come from the one institute they trace back to two independent breeding programmes. The first of these programmes is based on early-heading germplasm of Swiss origin (Aurora) (Humphreys 1989a). The high WSC trait in Aurora was shown to confer higher WSC than a number of other European (Humphreys 1989a) and Australasian cultivars (Radojevic et al. 1994; Smith et al. 1999). The trait has since been crossed into, and evaluated in, a range of genetic backgrounds in perennial ryegrass (Miller et al. 2001; Lee et al. 2001; Smith et al. 2001, 2002) resulting in cultivars such as Cariad, AberDove (Ba11353) and AberDawn (Ba10727) that have all been evaluated in experiments in Australia or New Zealand. A second germplasm pool independent of the Aurora derived material, based on a cross between northern Italian and 
north-western European germplasm, was used to develop the 'high sugar' cultivar AberDart (M.O. Humphreys pers. comm.) which is the 'high sugar' cultivar that is most widely available commercially.

\section{Performance of 'high sugar' grasses in Europe}

Aurora was compared to standard cultivars in several sheep grazing experiments in the UK (Davies et al. 1989a, 1989b, 1991, 1992; Munro et al. 1992). Sheep production from Aurora perennial ryegrass was compared to production from Aberystwyth S23 and Meltra (tetraploid) perennial ryegrass in mid-Wales over a 6year period (1985-1990) (Davies et al. 1989a, 1989b, 1991, 1992). In these experiments Aurora had higher WSC concentrations that S23. Differences were also observed in the sward height profiles between Aurora and the other cultivars, necessitating differences in stocking rate throughout the experiment. For instance, the mean stocking rate on pasture containing Aurora (22.6 ewes/ha) was $27 \%$ higher than Aberystwyth S23, and $17 \%$ higher than Meltra, during the period late-April to mid-July in the years 1985-1986 (Davies et al. 1989a).

It is unfortunately impossible to decide whether the increased animal production was due to changes in stocking rate, differences in herbage yield or differences in the nutritive value of the pastures. Inferences may be made on the relative potential for animal production of the different cultivars under this system of management. Lamb output per hectare was greater from Aurora than S23. The advantage ranged from $29 \%$ in the first year of the experiment (Davies et al. 1989b) to 7\% in years 4-6 of the experiment, with the advantage being $11 \%$ averaged over all 6 years (Davies et al. 1992). These differences were due to higher numbers of lambs grazing Aurora; the liveweight gains of individual lambs grazing Aurora pastures was not different from those grazing S23 pastures (Davies et al. 1989b). The increase in annual lamb production from Aurora pastures was largely due to better lamb production in the spring. Differences between the cultivars later in the season were less pronounced and not consistent (Davies et al. 1989b). Aurora proved to be less persistent than the other varieties. This accounted for some of the decline in the advantage of Aurora over the other cultivars in later years of the study (Davies et al. 1992).

Similar effects on lamb production per hectare were observed independently by Munro et al. (1992) who compared Aurora (early flowering) with the perennial ryegrass cultivars Frances (early flowering), Talbot (intermediate flowering), and Melle (late flowering). Over 2 years, lamb production from grass only swards of Aurora was 19\% higher than from Frances despite similar herbage production.

The development of AberDove perennial ryegrass, with high WSC concentrations but without the very early flowering characteristic of Aurora, has facilitated a number of comparisons with the standard cultivar AberElan. As occurred in the trial with Aurora, lamb production from AberDove compared to AberElan was higher $(23 \%)$ due to a combination of increased liveweight gain (12\%) and carrying capacity (Lee et al. 2001). When the AberDove and AberElan were grazed by dairy cattle (Miller et al. 2001) dry matter intake was not different but the higher digestibility of AberDove led to increased digestible DM intakes and a $21 \%$ increase in milk production during early lactation.

While the reports above are cited to demonstrate the potential of high sugar grasses to increase animal production, this is not always the case and further work is required to separate genetic, management and environmental effects on, firstly, the expression of the high sugar trait under grazing conditions and, secondly, the conversion of this to increased animal production.

\section{Performance of 'high sugar' grasses in Australasia}

It is clear that when 'high sugar' perennial ryegrass cultivars are grown in environments to which they are adapted and the trait is expressed, they can support higher levels of animal production. However, when these cultivars have been grown in Australia and New Zealand the results have been variable. High sugar cultivars were first sown at three sites in Australia in 1995 (Smith et al. 1998) and forage quality was evaluated at multiple harvests from 1995 - 1997. During this experiment, the WSC concentrations were most often significantly higher than the control cultivars Ellett, Vedette and Kangaroo Valley. The major exception was during periods when the high sugar lines were infected with crown rust, demonstrating the need to combine the high sugar trait with adequate levels of resistance to local strains of crown rust. Ellett was shown concurrently to have a relatively high WSC concentration when compared to the cohort of diploid perennial ryegrass cultivars that were commercially sown in Victoria in the mid-1990s (Smith et al. 2004).

In subsequent field trials in the Manawatu in New Zealand, the high WSC cultivar AberDart did not have significantly higher concentrations of WSC than the control cultivar Fennema (Parsons et al. 2004). Similarly, in Australia at Kyabram, AberDawn failed to exhibit higher WSC concentrations than the standard UK cultivar AberElan (Francis et al. 2006). The lack of consistent results with this germplasm is not surprising as material directly imported from Europe seldom performs well across the wide range of conditions in New Zealand and Australia. The variable expression of the high WSC trait in this germplasm in Australia and New Zealand, and the relatively few grazing trials done under our conditions, 
make it hard to assess the value of this trait in our environments, free of the confounding effects of both changes in management and the relatively poorly adapted genetic background of the germplasm.

While it is tempting to further review the large number of trials that have occurred on the high sugar grasses, Aurora and its derivatives, and AberDart, it is of more value to consider the prospects of developing high sugar grass cultivars that are well adapted to Australasian conditions. It is clear from the European experience that environmental conditions and management can have an effect on the expression of the high WSC trait. When high WSC are expressed and appropriate grazing management regimes are implemented, there can be significant increases in animal production.

In order for high WSC grass cultivars to be of consistent value in Australasia, the high WSC trait must be expressed in germplasm that is well adapted to our environments, has good levels of rust resistance, heat tolerance and persistence, all of which are non-trivial targets in perennial ryegrass breeding programmes. Therefore it will either be necessary to incorporate the high WSC trait that is present in these UK cultivars into adapted germplasm through backcrossing or to pursue an independent method of developing high WSC in regionally adapted germplasm.

The success of backcrossing to Australasian germplasm will depend on the complexity of control of the high WSC trait in these two sources from the UK and how well the germplasm combines with locally adapted material. The high WSC trait in Aurora has been shown to be under relatively simple genetic control (Humphreys et al. 1989a, 1989b) whereas the genetic control of the trait in AberDart is less well characterised. The development of molecular markers in perennial ryegrass (Smith et al. 2007) may facilitate the selection for high WSC trait free of the negative background effects of using poorly adapted germplasm.

An alternative approach is to directly seek to improve the WSC concentration of adapted germplasm. Consistent differences in the ranking of cultivars for nutritive value have been measured in some Australasian perennial ryegrass cultivars, although the actual levels of traits were affected by environmental effects such as temperature which were not associated with heritable genetic variation in two breeding populations (Smith et al. 2004). Therefore we are seeking to develop high WSC germplasm using modern breeding tools such as molecular markers and genetic modification to more robustly target genes involved in carbohydrate biosynthesis. The Molecular Plant Breeding CRC (MPBCRC) has commenced assessing genetic variation (haplotypes) within genes involved in fructan biosynthesis (Ponting et al. 2007) and is now determining the extent to which this variation is associated with phenotypic changes in the WSC concentration of elite perennial ryegrass plants.

We are also seeking through Gramina, a joint venture between MPBCRC and PGG Wrightson, to directly alter the expression of genes involved in fructan biosynthesis using genetic modification technologies. Four enzymes are required to produce fructans in perennial ryegrass: sucrose:sucrose 1-fructosyltransferase (1-SST); fructan:fructan 1-fructosyltransferase (1-FFT); 6-glucose fructosyltransferase (6G-FFT); and fructan:fructan 6fructosyltransferase (6-FFT) or sucrose:fructan 6fructosyltransferase (6-SFT). Fructan exohydrolases (FEH) are primarily responsible for the degradation of fructans while sucrose is degraded by invertase enzyme (INV) (Chalmers et al. 2005). We have identified the genes coding for these enzymes in perennial ryegrass (e.g. Lidgett et al. 2002) and have recently commenced developing plants with altered fructan biosynthesis.

Plants with over-expression of 1-SST were shown to have increased fructan concentrations in their stems when grown under controlled environment conditions and plants were free of stress (Cao et al. 2007). Further work is underway to confirm these results in the field and to further enhance the concentration of fructans in perennial ryegrass throughout plant development. While the development of this germplasm is still at the research phase, the development of perennial ryegrass genotypes with altered carbohydrate accumulation in isogenic lines, or at least in lines with very similar genetic backgrounds, will greatly aid the dissection of the benefits of high carbohydrate expression free from other effects related to the genetic background of the germplasm being evaluated.

\section{Conclusions}

The development of 'High Sugar' grasses that are adapted to Australasian conditions has the potential to increase the productivity of grazing systems. However, the high sugar trait cannot be considered in isolation and must be incorporated into germplasm that has high yield potential, disease resistance and heat tolerance for the trait to be robustly expressed in New Zealand and Australia.

\section{REFERENCES}

Beever, D.E. 1993. Ruminant production from forages: present and future opportunities. pp 535-542. In: Proceedings of the XVII International Grasslands Congress.

Cao, Y.; Martelotto, L.; Chalmers, J.; Liu, Z.; Griffith, M.; Chennareddy, S.; Fulgeras, K.; Dimech A.; Smith, K.F.; Mouradov, A.; Spangenberg, G. 2007. Molecular dissection of fructan metabolism in perennial ryegrass 
(Lolium perenne L.) Poster presentation \#59, Fifth International Symposium on the Molecular Breeding of Forage and Turf, Sapporo, Japan.

Chalmers, J.; Lidgett, A.; Cummings, N.; Cao, Y.; Forster, J.; Spangenberg, G. 2005. Molecular genetics of fructan metabolism in perennial ryegrass. Plant Biotechnology Journal. 3: 459-474.

Davies, D.A.; Fothergill, M.; Jones, D. 1989a. Frequency of stocking rate adjustments required on contrasting upland perennial ryegrass pastures continuously grazed to a sward height criterion from May to July. Grass and Forage Science 44: 213-221.

Davies, D.A.; Fothergill, M.; Jones, D. 1989b. Assessment of contrasting perennial ryegrasses, with and without white clover, under continuous sheep stocking in the uplands. 1. Animal production from the grass varieties. Grass and Forage Science 44: 431439.

Davies, D.A.; Fothergill, M.; Jones, D. 1991. Assessment of contrasting perennial ryegrasses, with and without white clover, under continuous sheep stocking in the uplands. 3. Herbage production, quality and intake. Grass and Forage Science 46: 39-49.

Davies, D.A.; Fothergill, M.; Morgan, C.T. 1992. Assessment of contrasting perennial ryegrasses, with and without white clover, under continuous sheep stocking in the uplands. 4. Animal production in years 4-6. Grass and Forage Science 47: 249-258.

Francis, S.A.; Chapman, D.F.; Doyle, P.T.; Leury, B.J. 2006. Dietary preferences of cows offered choices between white clover and 'high sugar' and 'typical' perennial ryegrass cultivars. Australian Journal of Experimental Agriculture 46: 1579-1587.

Humphreys, M.O. 1989a. Water-soluble carbohydrates in perennial ryegrass breeding. I. Genetic differences among cultivars and hybrid progeny grown as spaced plants. Grass and Forage Science 44: 231-236.

Humphreys, M.O. 1989b. Water-soluble carbohydrates in perennial ryegrass breeding. II. Cultivars and hybrid progeny performance in cut plots. Grass and Forage Science 44: 237-244.

Humphreys, M.O. 1989c. Water-soluble carbohydrates in perennial ryegrass breeding. III. Relationships with herbage production, digestibility and crude protein content. Grass and Forage Science 44: 423-430.

Lee, M.R.F.; Jones, E.L.; Moorby, J.M.; Humphreys, M.O.; Theodorou, M.K.; MacRae, J.C.; Scollan, N.D. 2001. Production responses from lambs grazed on Lolium perenne selected for an elevated water-soluble carbohydrate concentration. Animal Research 50: 441449.

Lidgett, A.; Jennings, K.; Johnson, X.; Guthridge, K.; Jones, E.; Spangenberg. G. 2002. Isolation and characterisation of fructosyltransferase gene from perennial ryegrass (Lolium perenne). Journal of Plant Physiology 159: 1037-1043.

Miller, L.A.; Moorby, J.M.; Davies, D.R.; Humphreys, M.O.; Scollan, N.D.; MacRae, J.C.; Theodorou, M.K. 2001. Increased concentration of water-soluble carbohydrate in perennial ryegrass (Lolium perenne L.): milk production from dairy cows. Grass and Forage Science 56: 383-394.

Munro, J.M.M.; Davies, D.A.; Evans, W.B.; Scurlock, R.V. 1992. Animal production of herbage varieties. 1. Comparison of Aurora with Frances, Talbot and Melle perennial ryegrass when grown alone and with white clover. Grass and Forage Science 47: 259-273.

Parsons, A.J.; Rasmussen, S.; Xue, H.; Newman, J.A.; Anderson, C.B.; Cosgrove, G.P. 2004. Some 'high sugar grasses' don't like it hot. Proceedings of the New Zealand Grassland Association 66: 265-271.

Ponting, R.C.; Drayton, M.C.; Cogan, N.O.I.; Dobrowolski, M.P.; Spangenberg, G.C.; Smith, K.F.; Forster, J.W. 2007. SNP discovery, validation, haplotype structure and linkage disequilibrium in fulllength herbage nutritive quality genes of perennial ryegrass (Lolium perenne L.) Molecular Genetics and Genomics: in press.

Radojevic, I.; Simpson, R.J.; St John, J.A.; Humphreys, M.O. 1994. Chemical composition and in vitro digestibility of lines of Lolium perenne selected for high concentrations of water-soluble carbohydrate. Australian Journal of Agricultural Research 45: 901912.

Smith, K.F.; Simpson, R.J.; Oram, R.N.; Lowe, K.F.; Evans, P.M.; Kelly, K. 1998. Seasonal variation in the herbage yield and nutritive value of perennial ryegrass (Lolium perenne L.) cultivars with high or normal water-soluble carbohydrate concentrations grown in three contrasting Australian dairy environments. Australian Journal of Experimental Agriculture 38: 821-830.

Smith, K.F.; Simpson, R.J.; Culvenor, R.A.; Oram, R.N.; Humphreys, M.O.; Prud'homme, M.P. 2001. The effects of ploidy and genes conferring a high watersoluble carbohydrate concentration on carbohydrate accumulation, nutritive value and morphology of perennial ryegrass (Lolium perenne L.) Journal of Agricultural Science, Cambridge 136: 65-74.

Smith, K.F.; Culvenor, R.A.; Humphreys, M.O.; Simpson, R.J. 2002. Growth and carbon partitioning in perennial ryegrass (Lolium perenne L.) cultivars selected for high water-soluble carbohydrate concentrations. Journal of Agricultural Science, Cambridge 138: 375-385.

Smith, K.F.; Simpson, R.J.; Oram, R.N. 2004. The effects of site and season on the yield and nutritive value of cultivars and half-sib families of perennial ryegrass 
(Lolium perenne L.). Australian Journal of Experimental Agriculture 44: 763-769.

Smith, K.F.; Forster, J.W.; Spangenberg, G.C. 2007. Converting genomic discoveries into genetic solutions for dairy pastures - an overview. Australian Journal of Experimental Agriculture 47: in press.
Smouter, H.; Simpson, R.J.; 1989. Occurrence of fructans in the Gramineae (Poaceae). New Phytologist 111: 35968.

Van Soest, P.J. 1978. Dietary fibers: their definition and nutritional properties. The American Journal of Clinical Nutrition 31: S12-S20. 